\title{
The evolution of the Ecdysozoa
}

\author{
Maximilian J. Telford*, Sarah J. Bourlat, Andrew Economou, \\ Daniel Papillon and Omar Rota-Stabelli \\ Department of Biology, University College London, Darwin Building, Gower Street, \\ London WC1E 6BT, UK
}

\begin{abstract}
Ecdysozoa is a clade composed of eight phyla: the arthropods, tardigrades and onychophorans that share segmentation and appendages and the nematodes, nematomorphs, priapulids, kinorhynchs and loriciferans, which are worms with an anterior proboscis or introvert. Ecdysozoa contains the vast majority of animal species and there is a great diversity of body plans among both living and fossil members. The monophyly of the clade has been called into question by some workers based on analyses of whole genome datasets. We review the evidence that now conclusively supports the unique origin of these phyla. Relationships within Ecdysozoa are also controversial and we discuss the molecular and morphological evidence for a number of monophyletic groups within this superphylum.
\end{abstract}

Keywords: Ecdysozoa; Arthropoda; Introverta; Protostomia; phylogeny; evolution

\section{INTRODUCTION}

The Ecdysozoa is a widely accepted clade that encompasses the Euarthropoda (Insecta, Crustacea, Myriapoda and Chelicerata), the arthropod-like Onychophora and Tardigrada and five phyla of introvert bearing worms: the Nematoda, Nematomorpha, Priapulida, Kinorhyncha and Loricifera. In terms of species numbers and niche diversity, the Ecdysozoa is far and away the most significant clade of animals with over a million described species and an estimated total of more than 4.5 million living species (Chapman 2005). The extraordinary number of insects is well known - there are estimated to be more than 10 times as many species of insects than there are of all the deuterostomes and lophotrochozoans put together-yet even had the founder of the insect lineage been eaten by a passing frog, the nematodes and the rest of the arthropods (myriapods, chelicerates and crustaceans) would still easily outnumber all other living animals by close to a quarter of a million species (Chapman 2005). Their characteristic tough cuticle also means that ecdysozoans are well represented in the fossil record adding further wonderful forms to the diversity of the phylum.

Despite the huge numbers of species and great niche diversity, the basic body plans of the Ecdysozoa are rather conservative, being either insect-like with a segmented body and jointed appendages or worm-like with an anterior circum-oesophageal nerve ring and a terminal mouth usually found on an introvert. All groups lack a primary larva as generally conceived and possess a moulted cuticle with concomitant lack of locomotory cilia; it is this periodic moulting or ecdysis that gives the assemblage its name. Although the morphological diversity of ecdysozoan phyla may be seen as fairly restrained when compared to the diversity of shapes seen

*Author for correspondence (m.telford@ucl.ac.uk).

One contribution of 17 to a Discussion Meeting Issue 'Evolution of the animals: a Linnean tercentenary celebration'. among, for example, Lophotrochozoa, these two ecdysozoan body plans happen to manifest themselves in the two most extensively and intensively studied invertebrates on the planet, the nematode Caenorhabditis elegans and the fruitfly Drosophila melanogaster.

Prior to 1997, the prevalent view of arthropod relationships linked them, via the onychophorans, to the annelid worms. This annelid-arthropod clade is called Articulata in recognition of the principal character uniting these phyla: a segmented body. Articulata was generally thought to be part of a larger assemblage of animal phyla linked by the possession of a coelomic cavity and called Coelomata. Although the alternative concept of a relationship between arthropods and pseudocoelomate worms such as nematodes and priapulids existed much earlier (discussed in Schmidt-Rhaesa 1998), the first support from molecular sequence data for such a relationship, and indeed the first reference to the Ecdysozoa, date to a paper by Aguinaldo et al. (1997).

This discussion is predicated on the assumption that the Ecdysozoa is a natural, monophyletic group. However, the existence of the Ecdysozoa is not yet universally accepted and so we will consider the evidence that has amassed in support of the monophyly of this group in the 10 years since the paper by Aguinaldo et al. The relationships among the introvertan worms, their position relative to Panarthropoda (Onychophora, Tardigrada and Euarthropoda) and several aspects of the phylogeny within Panarthropoda and Euarthropoda themselves are all still controversial and we will consider recent arguments around each of these.

\section{THE ECDYSOZOA IS A MONOPHYLETIC GROUP}

The initial support for the Ecdysozoa came from a study of small subunit (18S) ribosomal RNA (SSU rRNA) that specifically addressed one problem encountered when using molecular data derived from 
the $C$. elegans genome and many other nematodes (Aguinaldo et al. 1997). This problem derives from the fact that the $C$. elegans genome is rapidly evolving relative to those of other animals and is therefore perceived to be susceptible to the systematic phylogenetic error of long-branch attraction (LBA; Felsenstein 1978). This artefact of tree reconstruction would tend to cause the branch leading to the fast-evolving nematodes to be shifted towards the root of a tree. The use of short-branched nematodes in the analysis of Aguinaldo et al. resulted in the nematodes moving from their position close to the root of the bilaterian tree (one also supported by consideration of their morphology, in particular their lack of a coelomic cavity) to a close relationship with the arthropods and priapulid worms in a clade which the authors named, the Ecdysozoa (Aguinaldo et al. 1997).

Subsequent analyses of rRNAs have extended membership of the Ecdysozoa beyond Nematoda and Priapulida to include three further phyla of worms; Nematomorpha, Kinorhyncha and Loricifera. This clade had been anticipated by various authors who had already linked these five worm phyla in a group called the Cycloneuralia (Ahlrichs 1995) or Introverta (Nielsen 2001).

The monophyletic Ecdysozoa has been replicated by other taxonomically well-sampled datasets including combined small and large subunit (LSU) rRNAs (Mallatt \& Winchell 2002; Mallatt \& Giribet 2006) and myosin heavy-chain sequences (Ruiz-Trillo et al. 2002) as well as Hox gene signature peptides (de Rosa et al. 1999) and the (somewhat puzzling) shared presence, in the nervous system of all studied ecdysozoans, of an unidentified antigen recognized by the anti-horseradish peroxidase (HRP) antibody (Haase et al. 2001). The multimeric beta-thymosin gene found in flies and nematode worms (Manuel et al. 2000) has been shown not to be a synapomorphy of the Ecdysozoa (Telford 2004).

Despite these congruent results, there exists a powerful series of papers arguing against the close relationship of nematodes and arthropods and supporting instead the traditional view of the monophyletic Coelomata linking arthropods such as D. melanogaster to humans rather than to nematode worms (Blair et al. 2002; Wolf et al. 2004; Philip et al. 2005; Ciccarelli et al. 2006; Rogozin et al. 2007). This specific phylogenetic question has the attraction of being approachable with the largest possible molecular datasets, the completely sequenced genomes of flies, worms and humans. What almost all studies that have used this approach have found is that the evidence is strongly in favour of the Coelomata hypothesis and against Ecdysozoa.

The counter argument, naturally, is that these whole genome studies suffer from precisely the problem that the Aguinaldo et al. paper addressed; the systematic artefactual attraction of the nematode branch towards the root of the Bilateria due to LBA. This contention does seem to be borne out by a number of publications in the past few years. Copley et al. (2004) compared the presence or absence of 1712 genes or distinct combinations of protein domains specific either to flies and humans or to flies and nematode worms. There were many more of the former giving apparently strong support to the Coelomata hypothesis. However, they were able to show that this strong signal was an artefact resulting from a strong tendency towards secondary loss of genes in the nematode, a feature of its high rate of genomic evolution (Copley et al. 2004). In parallel, Philippe et al. (2005) used large 'phylogenomic' datasets (whole genomes combined with data from expressed sequence tag projects and hence having much broader taxon sampling) and showed that experiments designed to reduce potential long-branch effects-using less distant out-groups, selecting slowly evolving nematodes and discarding the more unevenly evolving genes-supported Ecdysozoa while Coelomata was supported without these efforts. Finally, Irimia et al. (2007) have used a similar approach to show that claims of an excess of identical, rarely changing amino acids shared by flies and humans and lacking in nematode worms (Rogozin et al. 2007), are biased by the use of distant out-groups and by the rapid evolution of C. elegans. They show that, when these biases are accounted for, there is significantly more support for Ecdysozoa than for Coelomata from this source of evidence (Irimia et al. 2007).

The phylogenomic approach has recently been extended to the slowly evolving Priapulida that are strongly supported as ecdysozoans (Webster et al. 2006; also true of Nematomorpha: T. Juliusdottir, R. Jenner, M. Telford \& R. Copley 2007, unpublished results). This result was further strengthened by analyses of the very arthropod-like mitochondrial genome of Priapulus caudatus. Perhaps even more strikingly, the priapulid mitochondrial gene order can be reconciled with that of the arthropods by a single inversion (Webster et al. 2007).

We would also like to highlight a further very convincing synapomorphy supporting the monophyly of Protostomia and hence, we believe, definitively ruling out the Coelomata hypothesis. Papillon et al. (2004) used the presence of a dozen rarely changing amino acids in the mitochondrial nad5 gene of protostomes as a striking indication that the chaetognaths were protostomes and not deuterostomes as traditionally believed. The signatures constitute a very complex, conserved, derived character defining a monophyletic group of Protostomia. We have extended this analysis of the nad5 gene, which appears to have undergone a significant burst of evolution within the lineage leading to the protostomes. Almost all of these signature amino acids are found in nematodes and priapulids as well as in other controversial protostomes including rhabditophoran and catenulid flatworms and lophophorates. A monophyletic Protostomia, while not specifically proving the existence of Ecdysozoa, is at least incompatible with a monophyletic group of coelomate animals and therefore contradicts the results from whole genome studies supporting Coelomata.

We strongly support the notion of a monophyletic Ecdysozoa and feel that the only opposing evidencethe whole genome support for Coelomata - is flawed by systematic error, which has been addressed successfully 
by much better taxon sampling, in particular the use of a close out-group (Philippe et al. 2005). In addition to the molecular systematic support, the monophyly of Ecdysozoa is supported by a number of synapomorphies including ecdysis of a trilayered cuticle (consisting of epi-, exo- and endocuticle), lack of locomotory cilia, lack of primary larva, terminal mouth and the HRP antigen in nervous system and conserved mitochondrial gene order that have been mentioned (see also Schmidt-Rhaesa 1998).

\section{CYCLONEURALIA, INTROVERTA, SCALIDOPHORA AND NEMATOIDA}

While we do not have an equivalent of the nad5 rare genomic change to support the monophyly of the Ecdysozoa within the Protostomia, as we have seen, we do have strong evidence from phylogenomic datasets of tens to hundreds of genes for the monophyly of Arthropoda plus Nematoda, Nematomorpha and Priapulida (Philippe et al. 2005; Webster et al. 2006). These three worm phyla had previously been linked to two further phyla, Kinorhyncha and Loricifera in a group collectively known as the Cycloneuralia (Ahlrichs 1995). The name refers to their collar-shaped, circum-oral brain; something similar is seen in Gastrotricha which are, however, lophotrochozoans not ecdysozoans (Telford et al. 2005). These phyla (but not Gastrotricha) also share an eversible anterior end, or introvert, which terminates in the mouth and gives the alternative name of Introverta (Nielsen 1995), although the introvert is only seen in the larvae of Nematomorpha and in isolated examples of Nematoda.

What we still do not have is much reliable information on the relationships between these phyla or their relationships to the Panarthropoda. This may be explained in part by the difficulty in working on the minute and hard to study Kinorhyncha and Loricifera.

The two groupings that do seem credible are a close relationship between Nematoda and Nematomorpha and between Priapulida and Kinorhyncha. Nematodes and nematomorphs share a number of characters, including the reduced circular muscles in the body wall, the cloaca seen in both sexes, the aflagellate sperm, the cuticle (collagenous not chitinous) and the ectodermal ventral and dorsal nerve cords and were grouped by Nielsen (1995) and named Nematoida by Schmidt-Rhaesa (1996). This clade has weak support from SSU analyses (Peterson \& Eernisse 2001), combined analyses of LSU and SSU rRNA (Mallatt et al. 2004) and from a small-scale phylogenomic analysis of 50 nuclear protein-coding genes (T. Juliusdottir, R. Jenner, M. Telford \& R. Copley 2007, unpublished results).

Morphologists have also united Priapulida, Kinorhyncha and Loricifera as the Scalidophora (Schmidt-Rhaesa 1998) or Cephalorhyncha (Nielsen 2001), on the basis of a shared introvert with scalids and the presence of two rings of retractor muscles on the introvert. The close relationship between priapulids and kinorhynchs at least seems to holdup based on the three gene sequences available from kinorhynchs but the single phylogenetic study including the Loricifera showed their position to be ambiguous (Park et al. 2006).

There is no clear indication that the Cycloneuralia is a monophyletic group and in fact most evidence points to Priapulida (and therefore Kinorhyncha too) being the earliest branch and the Nematoida being the sister group of the Panarthropoda (e.g. Mallatt \& Giribet 2006; Webster et al. 2006).

\section{PANARTHROPODA: EUARTHROPODA, TARDIGRADA AND ONYCHOPHORA}

The monophyly of the Euarthropoda plus Onychophora and Tardigrada seems, on the face of it, uncontentious. They are linked by a number of features, most important of which is the segmentally repeated limbs with terminal claws; Onychophora translates as 'claw-bearer'. The limbs in all three groups straddle parasegmental boundaries marked by the expression of the segment polarity gene engrailed (Patel et al. 1989; Gabriel \& Goldstein 2007; J. Eriksson 2007, personal communication). Their segmental paired, saccate nephridia (reduced in number and functioning as excretory organs in euarthropods) and open circulatory system also seem to be valid synapomorphies although both are missing in the miniaturized tardigrades (Hejnol \& Schnabel 2005). The circulatory system is characteristically formed as a fusion of both the coelomic cavities and the primary body cavity/embryonic blastocoel (i.e. a mixocoel) and there is a dorsal heart with characteristic openings (ostia) into the open circulatory system (Nielsen 2001).

Despite the characters in common with Panarthropoda, not all molecular studies support their monophyly, grouping Tardigrada with the nematodes rather than with Euarthropoda (see Lartillot \& Philippe 2008). However, if we assume that Panarthropoda is monophyletic, three trees could unite them: Euarthropoda with either Tardigrada or Onychophora, or Tardigrada and Onychophora as sister groups. The branching order of these three taxa is not resolved by molecules or morphology. However, if we assume that the small size of tardigrades is derived and accounts for the absence of mixocoel, heart and nephridia (Schmidt-Rhaesa 2001; characteristics found in Onychophora and Euarthropoda), we suggest that the similarities of cuticle, ganglionated ventral nerve chord and limbs in tardigrades and Euarthropoda may indicate a sister group relationship.

\section{EUARTHROPODA: MYRIOCHELATA VERSUS MANDIBULATA}

The relationships of the four euarthropod cladesChelicerata, Myriapoda, Crustacea and Hexapoda (Hexapoda $=$ Insecta, plus the basally branching groups Diplura, Protura and Collembola) have long been disputed. A decade or so ago there were even serious arguments over the single versus multiple origins of arthropodization, and therefore over the monophyly versus polyphyly of euarthropods (Fryer 1997). Molecular analyses have emphatically supported the monophyly of euarthropods and a unique origin of their cuticularized body and jointed appendages and in the 
past years, the attention has been focused more on the relationships between these four groups. One common feature of morphology based interpretations of arthropod phylogeny was the close relationship between Myriapoda and Hexapoda in a clade called the Atelocerata (which means malformed horns and refers to their common lack of a second antennal segment) defined additionally by unbranched (uniramous) appendages, malpighian tubules and tracheal breathing (Telford \& Thomas 1995). According to the polyphyleticists, the Atelocerata is grouped with the Onychophora in a clade called the Uniramia. Arguably, the clearest result to date in arthropod phylogeny shows that the insects are not most closely related to the myriapods but to the crustaceans (Boore et al. 1995) and, in all likelihood, constitute a subgroup within the Crustacea. This clade of crustaceans plus insects has been referred to as the Pancrustacea or as the Tetraconata due to the tetrapartite crystalline cones of the ommatidia (Dohle 1997, 2001; Harzsch 2004).

More controversial though, is the true position of Myriapoda which share numerous similarities of head organization not only with the insects (as discussed) but also with crustaceans, most notably the presence of a mandible on the third, appendagebearing head segment. The common head structure of myriapods, crustaceans and insects with two pairs of antennae (at least primitively), paired gnathobasic mandibles and two pairs of maxillae strongly supports their monophyly. This group is named the Mandibulata, reflecting the particular importance of detailed similarities seen between the mandibles of Pancrustacea and Myriapoda in terms of segmental identity, positioning relative to other body parts, gene expression, detailed similarities in terminal differentiation and, of course, in function (Scholz et al. 1998; Edgecombe et al. 2003; Harzsch et al. 2005).

Surprisingly, a number of molecular studies using rRNA, nuclear protein-coding genes and complete mitochondrial genome sequences do not support the mandibulate clade, instead linking the myriapods to the chelicerates in a group called the Paradoxopoda or the Myriochelata (Mallatt et al. 2004; Negrisolo et al. 2004; Pisani et al. 2004). An analysis of nuclear coding genes (Regier et al. 2005), however, did not find strong support for either Myriochelata or Mandibulata, suggesting that there is great uncertainty over the affinity of myriapods. Recognizing that the distinction between the two possibilities comes down to the position of the root of the euarthropod tree, we have reanalysed the complete mitochondrial genome sequences of various arthropods using a priapulid as a short-branched, phylogentically close relative of the arthropods. We find that, in contrast to previous studies that had used more distant out-groups (lophotrochozoans), our mitochondrial tree narrowly supports Mandibulata over Myriochelata (figure 1; see also Pisani 2004). We have also analysed a number of nuclear, protein-coding genes and have reached the same conclusion (figure 2). While our bias in support of a return to the Mandibulata is probably obvious, it is clear that this question remains to be resolved one way or the other.
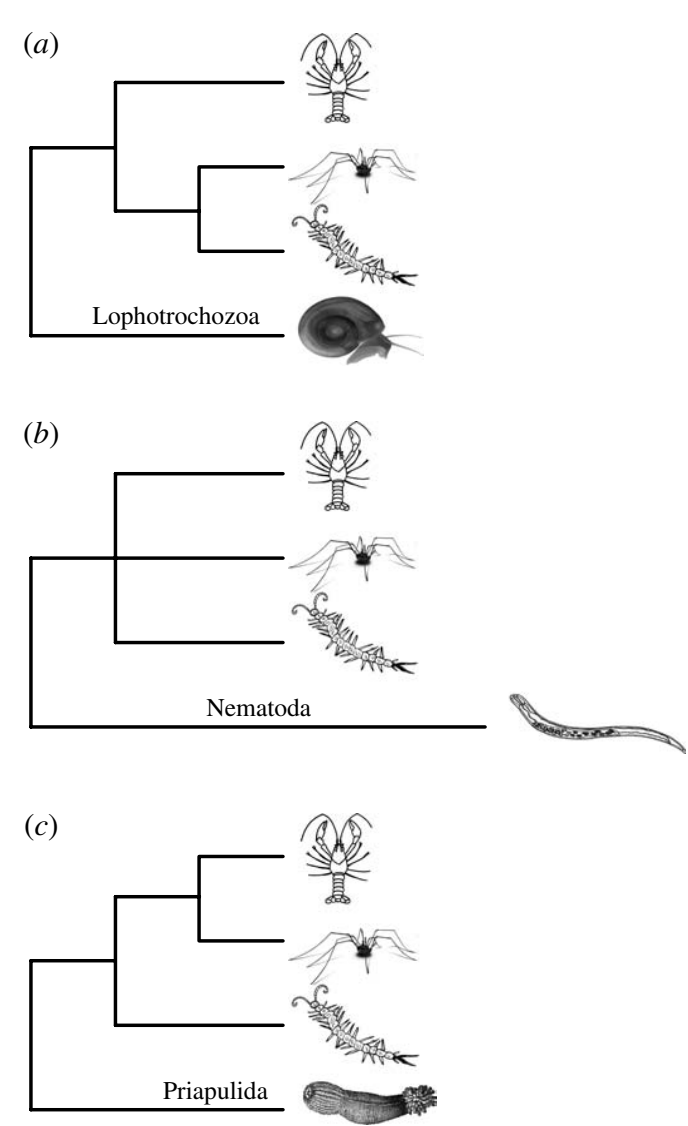

Figure 1. Different out-groups support different positions of the root of the Euarthropoda. (a) Support for Myriochelata (Myriapoda plus Chelicerata) is strong using mitochondrial when the Euarthropod tree is rooted using phylogenetically distant lophotrochozoans (Paradoxopoda). (b) Support is equivocal for either rooting using long branch but phylogenetically closer ecdysozoan nematodes (unresolved Euarthropoda). (c) The tree switches to supporting a monophyletic Mandibulata (Myriapoda with Crustacea and Hexapoda) when using the phylogenetically close and shortbranched priapulid as an out-group (O. Rota-Stabelli \& M. J. Telford 2007, unpublished results).

While there are specific characteristics shared by myriapods and chelicerates yet absent from Pancrustacea (Dove \& Stollewerk 2003; Kadner \& Stollewerk 2004; Stollewerk \& Simpson 2005), it is difficult to demonstrate these as synapomorphies as we have insufficient data from an out-group and the suspicion is that the Myriapoda/Chelicerata character state may be plesiomorphic and uninformative (Harzsch 2004; Harzsch et al. 2005). While the same criticism may be made of some of the characters supporting Mandibulata, the chelicerate homologue of the mandible (the first walking leg; Telford \& Thomas 1998) seems likely to represent the plesiomorphic condition as it strongly resembles adjacent, serially homologous, walking appendages. This implies that the mandible itself is a shared derived character uniting the mandibulates.

\section{PYCNOGONIDS ARE CHELICERATES}

The pycnogonids or sea spiders have long been associated with the chelicerates due to the shared character of chelicerae (chelifores in pycnogonids) on 


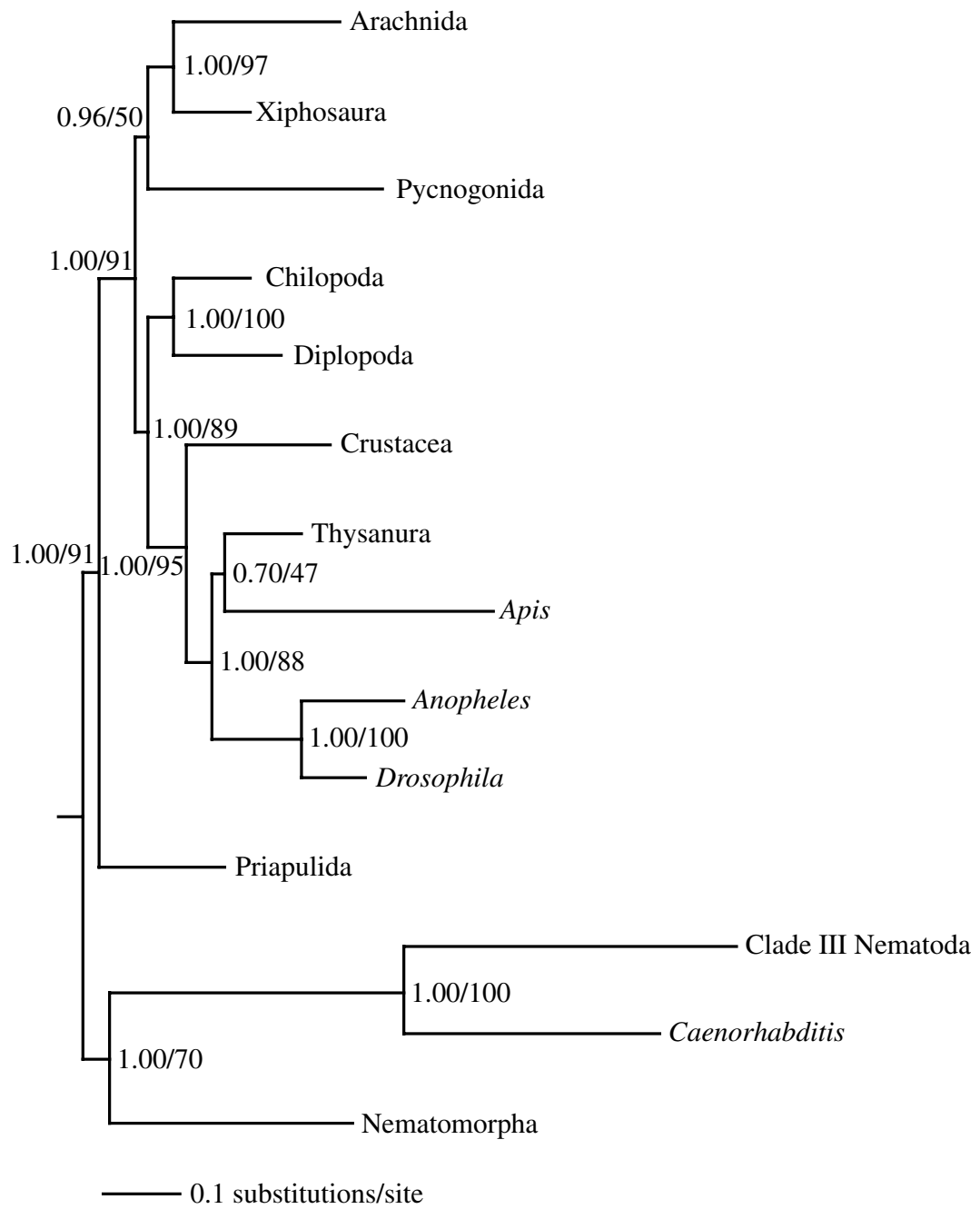

Figure 2. Phylogeny of the Ecdysozoa. Bayesian analysis using SSU and LSU ribosomal RNA sequences, complete mitochondrial genomes and eight nuclear protein-coding genes (Vacuolar ATP-synthase, enolase, Glyceraldehyde 3-phosphate dehydrogenase, carnitine palmitoyltransferase, Na/K ATPase, RNA Pol II, Dyskerin and EF 1-alpha). Some taxa with missing data have been merged into composite sequences. Support values shown as Bayesian posterior probabilities and nonparametric bootstrap.

the first limb-bearing segment. This phylogenetic link was questioned recently both by studies of their nervous systems and by molecular systematic analyses. The larval nervous system of a pycnogonid from the genus Anoplodactylus was studied and the chelifore appeared to be innervated from the frontmost portion of the brain (the protocerebrum), suggesting that this appendage was therefore not homologous to the chelicerae of other chelicerates which is innervated from the second portion of the brain-the deutocerebrum (Budd \& Telford 2005; Maxmen et al. 2005). This tied in with a molecular phylogenetic study placing the Pycnogonida at the base of Euarthropoda and not with Chelicerata (Regier et al. 2005). Subsequent analysis of Hox expression patterns have disproved the protocerebral position of the chelifores showing that they are indeed in the same deutocerebral position as chelicerae (Jager et al. 2006) and most molecular data imply that the chelicerates including Pycnogonida is a monophyletic group and that the contrary result is most likely derived from the rapid evolutionary rate of the Pycnogonida (Mallatt \& Giribet 2006).

\section{THE POSITION OF THE HEXAPODA WITHIN THE PANCRUSTACEA}

The support for the monophyly of Crustacea plus Hexapoda, which came most emphatically from the evidence of a shared mitochondrial genome rearrangement, has been bolstered by numerous subsequent molecular phylogenetic analyses (Friedrich \& Tautz 1995; Hwang et al. 2001; Delsuc et al. 2003; Nardi et al. 2003; Regier et al. 2005). Consideration of various aspects of morphology, in particular of nervous system ontogeny and structure, gives further weight to the integrity of this clade. Harzsch (2004) and Harzsch et al. (2005) list neuroblasts, two pairs of serotonergic neurons per hemineuromere, a fixed number of excitatory motoneurons per limb muscle and aspects of lateral eye ultrastructure in support of the Crustacea plus Hexapoda clade, which they term Tetraconata.

More controversial has been the placement of Hexapoda within Crustacea and the monophyly versus polyphyly of Hexapoda with a number of studies separating the Collembola from the Insecta. While it is generally agreed that Crustacea is paraphyletic rather than being the sister group of the Hexapoda (and that 


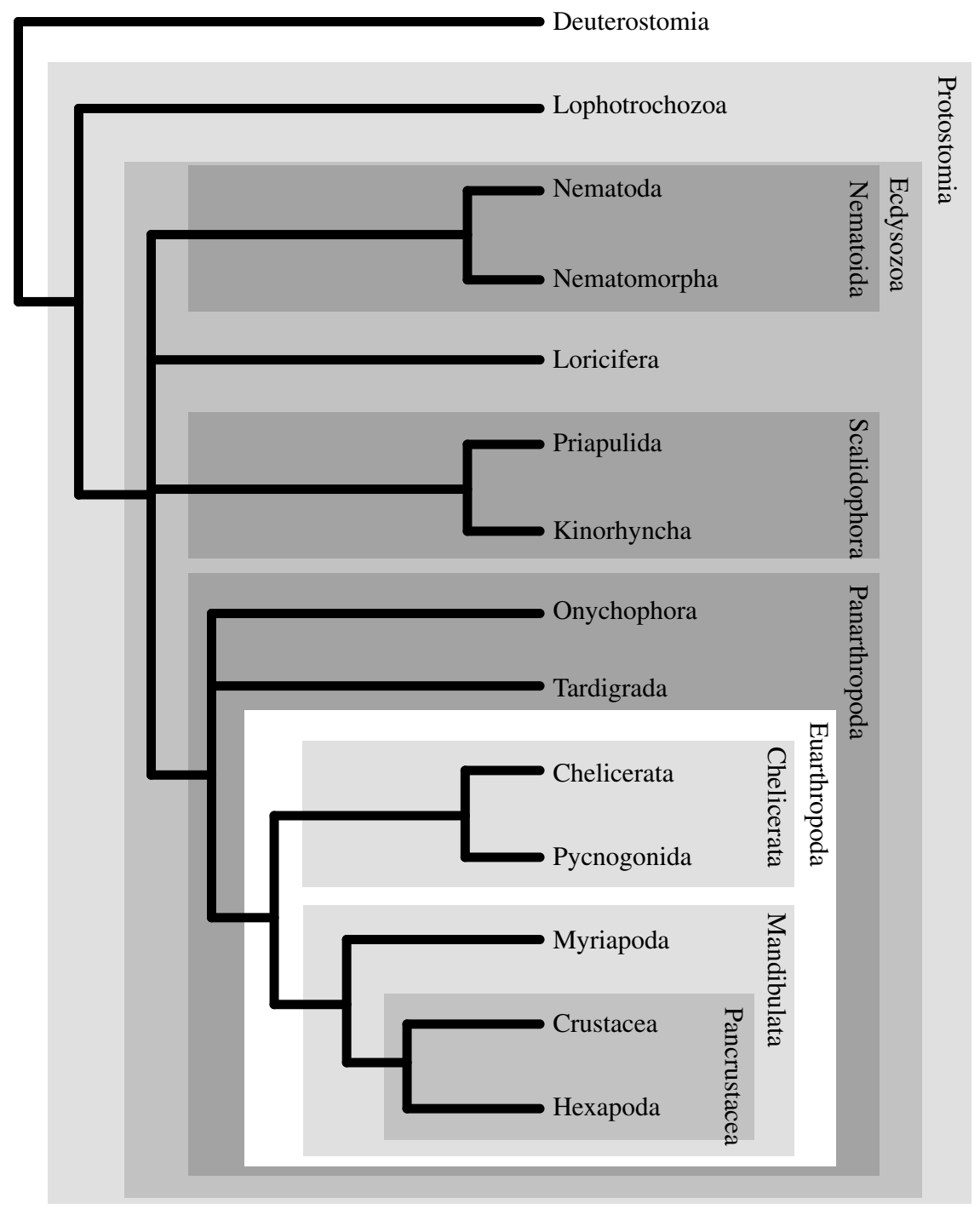

Figure 3. The phylogeny of the Ecdysozoa espoused in this manuscript. Names of probable monophyletic groups are given for each box. Unresolved portions of the tree are shown as multifurcations. We have shown Mandibulata (including Myriapoda) as monophyletic and Panarthropoda (including Tardigrada) as monophyletic groups despite some uncertainty over these groups as we feel the morphological evidence particularly convincing for these clades.

Hexapoda is in effect a terrestrial group of crustaceans), the closest crustacean sister group of the hexapods has been debated. Ignoring for the moment the little studied Cephalocarida and Remipedia, there are two contenders among the main crustacean classes: the Malacostraca that includes familiar species such as crabs and mantis shrimps and Branchiopoda such as Artemia the brine shrimp and Daphnia the water flea. The Hexapoda-Malacostraca clade is supported by various features of brain anatomy; specifically, members of these two groups share the presence of three brain neuropils joined by chiasmata where other crustaceans have two neuropils linked by parallel fibres (Harzsch 2002). Analyses of complete mitochondrial genome sequences on the other hand support a monophyletic Malacostraca and Branchiopoda clade as a sister group to Hexapoda (Cook et al. 2005). Most other molecular analyses, however, support a sister group relationship between Hexapoda and Branchiopoda (Regier et al. 2005; Mallatt \& Giribet 2006).

We have recently gathered all available data from rRNAs, mitochondrial genomes and various nuclear protein-coding genes, and our analyses support the close relationship between Hexapoda and Branchiopoda. This relationship is of great interest to the many workers interested in the evolution of the insects as it shows that Daphnia, a crustacean with a completely sequenced nuclear genome, is a relatively close sister group of insects. Our analyses also include data from Cephalocarida and Remipedia and the placement of these two groups is less certain. Both taxa are derived in terms of numbers of substitutions. While the remipede consistently groups close to the hexapods, the position of the cephalocarid is very unstable (A. Economou \& M. J. Telford 2007, unpublished results).

Although the relationships within the Hexapods are beyond the scope of this paper, the controversy over the placement of the Collembola is worth mentioning. While rRNA and nuclear coding gene phylogenies recover the expected monophyly of the hexapods (Insecta, Diplura, Protura and Collembola), analyses using complete mitochondrial genomes recover a diphyletic Hexapoda with the Insecta separated from the Collembola (Nardi et al. 2003); sequences for Diplura and Protura were not available. The basis of this result has been questioned by subsequent authors 
and one must conclude that, although monophyly of Hexapoda ultimately seems the most likely result, this needs to be tested with larger datasets.

\section{CONCLUSION}

In figure 3, we summarize our best current estimate of ecdysozoan phylogeny. The first thing that is obvious from this tree and from the preceding discussion is that, while it seems clear that Ecdysozoa is a monophyletic group, the relationships between phyla and major classes within the clade are often uncertain.

While the pattern of relationships of the Ecdysozoa has its own great intrinsic interest, the phylogeny should also be viewed as the basis for a further understanding of the evolution of the Ecdysozoa. The mapping of character states onto a phylogeny allows us to go beyond the relationships of organisms to the evolution of characters and ultimately a fuller understanding of the process of evolution. The characteristics of the common ancestor of Ecdysozoa is of particular interest and it can be safely assumed to have possessed the synapomorphies of the group; Budd has tentatively reconstructed the common ancestor as a large worm-like form with a terminal mouth (Budd 2001) and to these characteristics we can add the shared characters discussed previously. The monophyly versus paraphyly of the Cycloneuralia becomes important now as, if paraphyletic, then their common ancestor becomes synonymous with the ecdysozoan ancestor and suggests that it also possessed a cycloneuralian brain (not unreasonable considering the similar situation seen in onychophorans; Eriksson et al. 2003), and an introvert.

More controversial is the possibility that the ecdysozoan ancestor was segmented. While the kinorhynch metameres are generally referred to as zonites rather than segments, this seems a rather pointless distinction and is one indication that segmentation may be primitive in the group (Müller \& Schmidt-Rhaesa 2003; Schmidt-Rhaesa \& Rothe 2006). The similar deployment of homologous genes ('segment polarity' or 'pair rule' genes) in arthropods and kinorhynchs would be a more direct indication of homology and hence common ancestry of segmentation within the group as would the demonstration that arthropod segmentation can be convincingly homologized with that of annelids (Prud'homme et al. 2003) or even vertebrates (Damen 2007).

Through comparison of the completely sequenced genomes of D. melanogaster and C. elegans, there is also the theoretical possibility of learning something about the genome of the ecdysozoan common ancestor, or perhaps something close to it depending on the position of the Arthropoda/Nematoida common ancestor. One significant conclusion from comparative genomics to date has been the secondary loss of large numbers of genes in the two model ecdysozoans (Copley et al. 2004; Putnam et al. 2007). The problem, of course, is that the two model species appear to have much derived genomes making comparisons particularly difficult to interpret - are they different from other animals due to common ecdysozoan gene losses or through convergent gene losses in these two derived models? The ecdysozoan genome projects ongoing or recently announced, in particular that of the priapulid $P$. caudatus, are very exciting for the purpose of reconstructing the ancestral ecdysozoan genome, and should also add further to our understanding of the evolutionary relationships of this huge, diverse and fascinating group.

Research in the laboratory was supported by the BBSRC and by the Marie Curie RTN ZOONET (MRTN-CT-2004005624). We are very grateful for careful reviews by Andreas Schmidt-Rhaesa and Davide Pisani.

\section{REFERENCES}

Aguinaldo, A. A., Turbeville, J. M., Linford, L. S., Rivera, M. C., Garey, J. R., Raff, R. A. \& Lake, J. A. 1997 Evidence for a clade of nematodes, arthropods and other moulting animals. Nature 387, 489-493. (doi:10.1038/ 387489a0)

Ahlrichs, W. 1995 Ultrastruktur und Phylogenie von Seison nebaliae (Grube 1859) und Seison annulatus (Claus 1876). Hypothesen zu phylogenetischen Verwandtschaftsverhältnissen innerhalb der Bilateria. Göttingen, Germany: Cuvillier Verlag.

Blair, J. E., Ikeo, K., Gojobori, T. \& Hedges, S. B. 2002 The evolutionary position of nematodes. BMC Evol. Biol. 2, 7. (doi:10.1186/1471-2148-2-7)

Boore, J. L., Collins, T. M., Stanton, D., Daehler, L. L. \& Brown, W. M. 1995 Deducing the pattern of arthropod phylogeny from mitochondrial DNA rearrangements. Nature 376, 163-165. (doi:10.1038/376163a0)

Budd, G. E. 2001 Tardigrades as 'stem-group Arthropods': the evidence from the Cambrian fauna. Zool. Anz. 240, 265-279. (doi:10.1078/0044-5231-00034)

Budd, G. E. \& Telford, M. J. 2005 Evolution: along came a sea spider. Nature 437, 1099-1102. (doi:10.1038/437 1099a)

Chapman, A. 2005 Numbers of living species in Australia and the World. Report, Department of the Environment and Heritage, Canberra, Australia.

Ciccarelli, F. D., Doerks, T., von Mering, C., Creevey, C. J., Snel, B. \& Bork, P. 2006 Toward automatic reconstruction of a highly resolved tree of life. Science 311, 1283-1287. (doi:10.1126/science.1123061)

Cook, C. E., Yue, Q. \& Akam, M. 2005 Mitochondrial genomes suggest that hexapods and crustaceans are mutually paraphyletic. Proc. R. Soc. B 272, 1295-1304. (doi:10.1098/rspb.2004.3042)

Copley, R. R., Aloy, P., Russell, R. B. \& Telford, M. J. 2004 Systematic searches for molecular synapomorphies in model metazoan genomes give some support for Ecdysozoa after accounting for the idiosyncrasies of Caenorhabditis elegans. Evol. Dev. 6, 164-169. (doi:10. 1111/j.1525-142X.2004.04021.x)

Damen, W. G. 2007 Evolutionary conservation and divergence of the segmentation process in arthropods. Dev. Dyn. 236, 1379-1391. (doi:10.1002/dvdy.21157)

Delsuc, F., Philips, M. J. \& Penny, D. 2003 Comment on "hexapod origins: monophyletic or paraphyletic?". Science 301, 1482-1483. (doi:10.1126/science.1086558)

de Rosa, R., Grenier, J. K., Andreeva, T., Cook, C. E., Adoutte, A., Akam, M., Carroll, S. B. \& Balavoine, G. 1999 Hox genes in brachiopods and priapulids: implications for protostome evolution. Nature 399, 772-776. (doi:10.1038/21631)

Dohle, W. 1997 Are the insects more closely related to the crustaceans than to the myriapods? Entomol. Scand. Suppl. $51,7-16$. 
Dohle, W. 2001 Are the insects terrestrial crustaceans? A discussion of some new facts and arguments and the proposal of a proper name "Tetraconata" for the monophyletic unit Crustacea+Hexapoda. Ann. Soc. Entomol. France 37, 85-103.

Dove, H. \& Stollewerk, A. 2003 Comparative analysis of neurogenesis in the myriapod Glomeris marginata (Diplopoda) suggests more similarities to chelicerates than to insects. Development 130, 2161-2171. (doi:10.1242/dev. 00442)

Edgecombe, G., Richter, S. \& Wilson, G. 2003 The mandibular gnathal edges: homologous structures throughout Mandibulata? Afr. Invert. 44, 115-135.

Eriksson, B. J., Tait, N. N. \& Budd, G. E. 2003 Head development in the onychophoran Euperipatoides kanangrensis with particular reference to the central nervous system. F. Morphol. 255, 1-23. (doi:10.1002/jmor.10034)

Felsenstein, J. 1978 Cases in which parsimony or compatibility methods will be positively misleading. Syst. Zool. 27, 401-410. (doi:10.2307/2412923)

Friedrich, M. \& Tautz, D. 1995 rDNA phylogeny of the major extant arthropod classes and the evolution of myriapods. Nature 376, 165-167. (doi:10.1038/ $376165 \mathrm{a} 0)$

Fryer, G. 1997 A defence of arthropod polyphyly. In Arthropod relationships, vol. 55 (eds R. A. Fortey \& R. H. Thomas), pp. 23-33. London, UK: Chapman and Hall.

Gabriel, W. N. \& Goldstein, B. 2007 Segmental expression of Pax3/7 and engrailed homologs in tardigrade development. Dev. Genes Evol. 217, 421-433. (doi:10.1007/s00427-0070152-5)

Haase, A., Stern, M., Wächtler, K. \& Bicker, G. 2001 A tissue-specific marker of Ecdysozoa. Dev. Genes Evol. 211, 428-433. (doi:10.1007/s004270100173)

Harzsch, S. 2002 The phylogenetic significance of crustacean optic neuropils and chiasmata: a re-examination. F. Comp. Neurol. 453, 10-21. (doi:10.1002/cne.10375)

Harzsch, S. 2004 Phylogenetic comparison of serotoninimmunoreactive neurons in representatives of the Chilopoda, Diplopoda, and Chelicerata: implications for arthropod relationships. F. Morphol. 259, 198-213. (doi:10.1002/jmor.10178)

Harzsch, S., Müller, C. H. \& Wolf, H. 2005 From variable to constant cell numbers: cellular characteristics of the arthropod nervous system argue against a sister-group relationship of Chelicerata and "Myriapoda" but favour the Mandibulata concept. Dev. Genes Evol. 215, 53-68. (doi:10.1007/s00427-004-0451-z)

Hejnol, A. \& Schnabel, R. 2005 The eutardigrade Thulinia stephaniae has an indeterminate development and the potential to regulate early blastomere ablations. Development 132, 1349-1361. (doi:10.1242/dev.01701)

Hwang, U. W., Friedrich, M., Tautz, D., Park, C. J. \& Kim, W. 2001 Mitochondrial protein phylogeny joins myriapods with chelicerates. Nature 413, 154-157. (doi:10.1038/ 35093090)

Irimia, M., Maeso, I., Penny, D., Garcia-Fernàndez, J. \& Roy, S. W. 2007 Rare coding sequence changes are consistent with Ecdysozoa, not Coelomata. Mol. Biol. Evol. 24, 1604-1607. (doi:10.1093/molbev/msm 105)

Jager, M., Murienne, J., Clabaut, C., Deutsch, J., Le Guyader, H. \& Manuel, M. 2006 Homology of arthropod anterior appendages revealed by Hox gene expression in a sea spider. Nature 441, 506-508. (doi:10.1038/ nature04591)

Kadner, D. \& Stollewerk, A. 2004 Neurogenesis in the chilopod Lithobius forficatus suggests more similarities to chelicerates than to insects. Dev. Genes Evol. 214, 367-379. (doi:10.1007/s00427-004-0419-z)
Lartillot, N. \& Philippe, H. 2008 Improvement of molecular phylogenetic inference and the phylogeny of Bilateria. Phil. Trans. R. Soc. B 363, 1463-1472. (doi:10.1098/rstb. 2007.2236)

Mallatt, J. \& Giribet, G. 2006 Further use of nearly complete $28 \mathrm{~S}$ and $18 \mathrm{~S}$ rRNA genes to classify Ecdysozoa: 37 more arthropods and a kinorhynch. Mol. Phylogenet. Evol. 40, 772-794. (doi:10.1016/j.ympev.2006.04.021)

Mallatt, J. \& Winchell, C. J. 2002 Testing the new animal phylogeny: first use of combined large-subunit and smallsubunit rRNA gene sequences to classify the protostomes. Mol. Biol. Evol. 19, 289-301.

Mallatt, J. M., Garey, J. R. \& Shultz, J. W. 2004 Ecdysozoan phylogeny and bayesian inference: first use of nearly complete $28 \mathrm{~S}$ and $18 \mathrm{~S}$ rRNA gene sequences to classify the arthropods and their kin. Mol. Phylogenet. Evol. 31, 178-191. (doi:10.1016/j.ympev.2003.07.013)

Manuel, M., Kruse, M., Muller, W. E. G. \& Le Parco, Y. 2000 The comparison of b-thymosin homologues among Metazoa supports an arthropod-nematode clade. F. Mol. Evol. 51, 378-381.

Maxmen, A., Browne, W. E., Martindale, M. Q. \& Giribet, G. 2005 Neuroanatomy of sea spiders implies an appendicular origin of the protocerebral segment. Nature 437, 1144-1148. (doi:10.1038/nature03984)

Müller, M. C. \& Schmidt-Rhaesa, A. 2003 Reconstruction of the muscle system in Antygomonas sp. (Kinorhyncha, Cyclorhagida) by means of phalloidin labeling and cLSM. F. Morphol. 256, 103-110. (doi:10.1002/jmor.10058)

Nardi, F., Spinsanti, G., Boore, J. L., Carapelli, A., Dallai, R. \& Frati, F. 2003 Hexapod origins: monophyletic or paraphyletic? Science 299, 1887-1889. (doi:10.1126/ science.1078607)

Negrisolo, E., Minelli, A. \& Valle, G. 2004 The mitochondrial genome of the house centipede Scutigera and the monophyly versus paraphyly of myriapods. Mol. Biol. Evol. 21, 770-780. (doi:10.1093/molbev/msh078)

Nielsen, C. 1995 Animal evolution. Interrelationships of the living phyla, 1st edn. Oxford, UK: Oxford University Press.

Nielsen, C. 2001 Animal evolution. Interrelationships of the living phyla, 2nd edn. Oxford, UK: Oxford University Press.

Papillon, D., Perez, Y., Caubit, X. \& Le Parco, Y. 2004 Identification of chaetognaths as protostomes is supported by the analysis of their mitochondrial genome. Mol. Biol. Evol. 21, 2122-2129. (doi:10.1093/molbev/msh229)

Park, J. K., Rho, H. S., Kristensen, R. M., Kim, W. \& Giribet, G. 2006 First molecular data on the phylum Loricifera: an investigation into the phylogeny of Ecdysozoa with emphasis on the positions of Loricifera and Priapulida. Zool. Sci. 23, 943-954. (doi:10.2108/zsj.23.943)

Patel, N. H., Martin-Blanco, E., Coleman, K. G., Poole, S. J., Ellis, M. C., Kornberg, T. B. \& Goodman, C. S. 1989 Expression of engrailed proteins in arthropods, annelids, and chordates. Cell 58, 955-968. (doi:10.1016/00928674(89)90947-1)

Peterson, K. J. \& Eernisse, D. J. 2001 Animal phylogeny and the ancestry of bilaterians: inferences from morphology and 18S rDNA gene sequences. Evol. Dev. 3, 170-205. (doi:10.1046/j.1525-142x.2001.003003170.x)

Philip, G. K., Creevey, C. J. \& McInerney, J. O. 2005 The Opisthokonta and the Ecdysozoa may not be clades: stronger support for the grouping of plant and animal than for animal and fungi and stronger support for the Coelomata than Ecdysozoa. Mol. Biol. Evol. 22, 1175-1184. (doi:10.1093/molbev/msi102)

Philippe, H., Lartillot, N. \& Brinkmann, H. 2005 Multigene analyses of bilaterian animals corroborate the monophyly of Ecdysozoa, Lophotrochozoa, and Protostomia. Mol. Biol. Evol. 22, 1246-1253. (doi:10.1093/molbev/msi111) 
Pisani, D. 2004 Identifying and removing fast-evolving sites using compatibility analysis: an example from the Arthropoda. Syst. Biol. 53, 978-989. (doi:10.1080/ 10635150490888877)

Pisani, D., Poling, L. L., Lyons-Weiler, M. \& Hedges, S. B. 2004 The colonization of land by animals: molecular phylogeny and divergence times among arthropods. $B M C$ Biol. 2, 1. (doi:10.1186/1741-7007-2-1)

Prud'homme, B., de Rosa, R., Arendt, D., Julien, J. F., Pajaziti, R., Dorresteijn, A. W., Adoutte, A., Wittbrodt, J. \& Balavoine, G. 2003 Arthropod-like expression patterns of engrailed and wingless in the annelid Platynereis dumerilii suggest a role in segment formation. Curr. Biol. 13, 1876-1881. (doi:10.1016/j.cub.2003.10.006)

Putnam, N. H. et al. 2007 Sea anemone genome reveals ancestral eumetazoan gene repertoire and genomic organization. Science 317, 86-94. (doi:10.1126/science. 1139158)

Regier, J. C., Shultz, J. W. \& Kambic, R. E. 2005 Pancrustacean phylogeny: hexapods are terrestrial crustaceans and maxillopods are not monophyletic. Proc. $R$. Soc. B 272, 395-401. (doi:10.1098/rspb.2004.2917)

Rogozin, I. B., Wolf, Y. I., Carmel, L. \& Koonin, E. V. 2007 Ecdysozoan clade rejected by genome-wide analysis of rare amino acid replacements. Mol. Biol. Evol. 24, 1080-1090. (doi:10.1093/molbev/msm029)

Ruiz-Trillo, I., Paps, J., Loukota, M., Ribera, C., Jondelius, U., Baguñà, J. \& Riutort, M. 2002 A phylogenetic analysis of myosin heavy chain type II sequences corroborates that Acoela and Nemertodermatida are basal bilaterians. Proc. Natl Acad. Sci. USA 99, 11 246-11 251. (doi:10.1073/ pnas.172390199)

Schmidt-Rhaesa, A. 1996 The nervous system of Nectonema munidae and Gordius aquaticus, with implications on the ground pattern of the Nematomorpha. Zoomorphology 116, 133-142.

Schmidt-Rhaesa, A. 1998 The position of the Arthropoda in the phylogenetic system. f. Morphol. 238, 263-285. (doi:10.1002/(SICI)1097-4687(199812)238:3<263::AID -JMOR1 > 3.0.CO;2-L)

Schmidt-Rhaesa, A. 2001 Tardigrades-are they really miniaturized dwarfs? Zool. Anz. 240, 549-555. (doi:10. 1078/0044-5231-00066)
Schmidt-Rhaesa, A. \& Rothe, B. H. 2006 Postembryonic development of longitudinal musculature in Pycnophyes kielensis (Kinorhyncha, Homalorhagida). Integr. Comp. Biol. 46, 144-150. (doi:10.1093/icb/icj019)

Scholz, G., Mittmann, B. \& Gerberding, M. 1998 The pattern of Distal-less expression in the mouthparts of crustaceans, myriapods and insects: new evidence for a gnathobasic mandible and the common origin of the Mandibulata. Int. F. Dev. Biol. 42, 801-810.

Stollewerk, A. \& Simpson, P. 2005 Evolution of early development of the nervous system: a comparison between arthropods. BioEssays 27, 874-883. (doi:10. 1002/bies.20276)

Telford, M. J. 2004 The multimeric b-thymosin found in nematodes and arthropods is not a synapomorphy of the Ecdysozoa. Evol. Dev. 6, 90-94. (doi:10.1111/j.1525142X.2004.04013.x)

Telford, M. J. \& Thomas, R. H. 1995 Demise of the Atelocerata? Nature 376, 123-124. (doi:10.1038/ 376123a0)

Telford, M. J. \& Thomas, R. H. 1998 Expression of homeobox genes shows chelicerate arthropods retain their deutocerebral segment. Proc. Natl Acad. Sci. USA 95, 10 671-10 675. (doi:10.1073/pnas.95.18.10671)

Telford, M. J., Wise, M. J. \& Gowri-Shankar, V. 2005 Consideration of RNA secondary structure significantly improves likelihood-based estimates of phylogeny: examples from the bilateria. Mol. Biol. Evol. 22, 1129-1136. (doi:10.1093/molbev/msi099)

Webster, B. L., Copley, R. R., Jenner, R. A., MackenzieDodds, J. A., Bourlat, S. J., Rota-Stabelli, O., Littlewood, D. T. J. \& Telford, M. J. 2006 Mitogenomics and phylogenomics reveal priapulid worms as extant models of the ancestral Ecdysozoan. Evol. Dev. 8, 502-510. (doi:10.1111/j.1525-142X.2006.00123.x)

Webster, B. L., Mackenzie-Dodds, J. A., Telford, M. J. \& Littlewood, D. T. J. 2007 The mitochondrial genome of Priapulus caudatus Lamarck (Priapulida: Priapulidae). Gene 389, 96-105. (doi:10.1016/j.gene.2006.10.005)

Wolf, Y. I., Rogozin, I. B. \& Koonin, E. V. 2004 Coelomata and not Ecdysozoa: evidence from genome-wide phylogenetic analysis. Genome Res. 14, 29-36. (doi:10.1101/gr. 1347404) 